\title{
Planning and Setting Up of a Communication Program for Hospitalized COVID-19 Patients: Challenges and Potential Solutions in Resource Constrained Setting
}

\author{
Samridhi Nanda ${ }^{1}$ Sudip Kumar Datta ${ }^{20}$ \\ Ankit Sodani ${ }^{1}$ Anjan Trikha ${ }^{1}$ \\ ${ }^{1}$ Department of Anaesthesia, Pain Medicine and Critical Care, AlIMS, \\ New Delhi, India \\ ${ }^{2}$ Department of Laboratory Medicine, AlIMS, New Delhi, India \\ ${ }^{3}$ Department of Otorhinolaryngology, AlIMS, New Delhi, India \\ ${ }^{4}$ Department of Reproductive Biology, AlIMS, New Delhi, India \\ ${ }^{5}$ Department of Rheumatology, AlIMS, New Delhi, India
}

\author{
Prem Sagar $^{3}$ Mona Sharma ${ }^{4}$ Ranjan Gupta ${ }^{5}$
}

J Lab Physicians 2022;14:32-36.

\begin{abstract}
Address for correspondence Sudip Kumar Datta, MBBS, MD, Department of Laboratory Medicine, AlIMS, New Delhi, 110029, India (e-mail: dr.sudipdatta@gmail.com).
\end{abstract}

\begin{abstract}
Keywords

- COVID-19

- communication

- family-counseling

- stress prevention

- anxiety mitigation
\end{abstract}

Background The recent onset of COVID-19 pandemic has necessitated many patients to be hospitalized in the COVID-19 treating centers. Owing to the need for isolation of these patients and minimizing the risk of transmission to healthy people, COVID-19positive patients are completely restricted from meeting their friends and families. This gives rise to anxiety amongst the patients' relatives as they are not able to monitor the progress of the patients and have to depend entirely on the healthcare staff for any updates regarding the patient. In contrast, the treating doctors are undergoing severe stress due to the unknown nature of the virus and the risks involved in treating patients. They are thoroughly exhausted after the long hours donning the personal protection equipment (PPE).

Objective To structure and form an interface for communication between the treating physician and the families, as a "communication team," to decrease the workload on the treating physicians and minimize their contact time in a COVID-19 setting.

Results The addition of a communication team improved the physicians' efficiency of patient management and family satisfaction. Several challenges were faced during the setting up of this interface effectively. However, most of these were dealt with along the way. The communication team was instrumental in allaying the anxiety of the family with respect to their patients' clinical condition. This also ensured engagement of doctors from non-clinical and laboratory-based departments in the COVID-19 treatment process.

Conclusion Adding up a communication team for communicating clinical updates to the family in a resource-limited scenario greatly improved communication and thus family satisfaction of the COVID-19-positive patients. published online November 10, 2021
DOI https://doi.org/ 10.1055/s-0041-1736521. ISSN $0974-2727$.

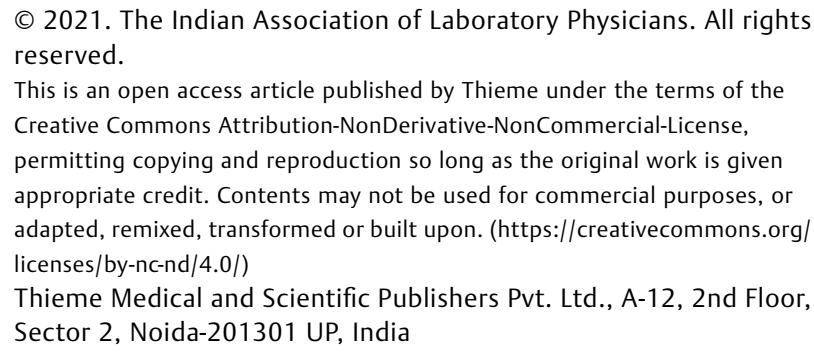

(c) 2021. The Indian Association of Laboratory Physicians. All rights reserved.

This is an open access article published by Thieme under the terms of the Creative Commons Attribution-NonDerivative-NonCommercial-License, permitting copying and reproduction so long as the original work is given appropriate credit. Contents may not be used for commercial purposes, or adapted, remixed, transformed or built upon. (https://creativecommons.org/ licenses/by-nc-nd/4.0/)

Thieme Medical and Scientific Publishers Pvt. Ltd., A-12, 2nd Floor, Sector 2, Noida-201301 UP, India 


\section{Introduction}

The COVID-19 pandemic caused by the novel corona virus (SARS CoV2) has been playing havoc worldwide. A series of acute atypical respiratory diseases was first reported in December 2019, from Wuhan, Hubei Province, China, and a novel coronavirus, now named as SARS-CoV-2, was identified as the causative agent. ${ }^{1}$ On January 30,2020 , the World Health Organization (WHO) declared the outbreak of COVID19 as a public health emergency of international concern. ${ }^{2}$ As stated by the emergency committee in the WHO situation report-12, the spread of COVID-19 may be terminated by early detection, isolation, prompt treatment, and the implementation of contact tracing. As per the WHO situation report-198, dated August 5, 2020, more than 18 million people worldwide have been affected by the virus with almost 700,000 deaths. ${ }^{3}$ These numbers are increasing by the day and causing a lot of panic.

Being a novel disease, having no effective treatment or vaccine, the crux of preventive strategy rests on limiting infection. COVID-19 is considered to get transmitted through droplets, fomites, and is possibly air-borne. ${ }^{4}$ However, if effective prevention strategies are implemented, the risk of infection through surface and aerosols reduces. ${ }^{5}$ Due to the unpredictable mortality associated with this SARS infection, and higher risk of infection amongst the healthcare providers, ${ }^{6}$ the panic and fear among the public, as well as, healthcare workers is disproportionately high. Hence, as per infection prevention strategies prescribed by the government, hospitals have been designated as "COVID-19 hospitals" or, the COVID-19 treating areas are cordoned off from non-COVID-19 areas. In the COVID-19 designated areas, unnecessary interaction of healthy people with patients are totally restricted. Due to the highly infectious nature of the disease, the family members or attendants of the patients are not allowed to meet the patients and most often are not even able to talk to them. Hence, after admitting their patients, the relatives are often oblivious to their patients' condition on a day to day basis. Therefore, a communication team was planned acting as a channel between the hospital care system and patient relatives.

\section{Materials and Methods}

The plan for communication team was made to have a better interaction between healthcare workers at the COVID center, AIIMS, New Delhi, and the patient's relatives. The communication team comprised six doctors from various specialtiesclinical as well as non-clinical. Both faculty and residents made up the team. The mix of clinical and non-clinical branches was mutually beneficial and collectively efficient. The clinical branches, by virtue of their routine practice, were proficient communicators, whereas, others, in due course learnt the tricks of the trade and were instrumental in making a strong and effective communication team, thereby not only increasing the work force but also catering to an essential part of patient management. The knowledge of non-clinical aspects of patient care such as laboratory testing was also helpful in building a holistic approach to the patient-care-communication. The team was rotated amongst themselves to break monotony and improve efficiency. The team acted as an interface between the treating team and the patients' relatives as depicted in - Fig. 1 .

The principal responsibilities of the communication team were obtaining information from the treating physicians, obtaining and compiling patient-related database from the

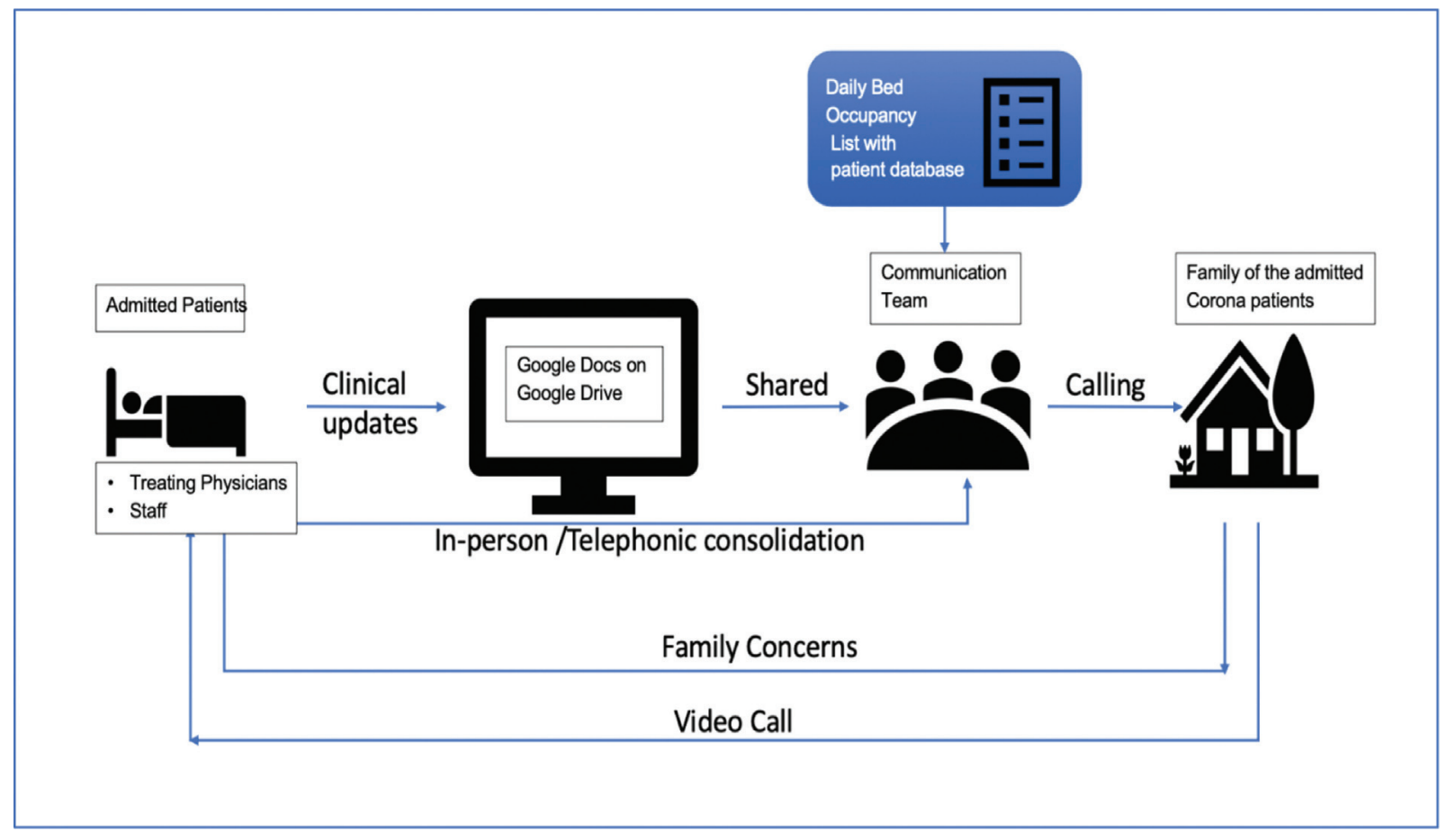


admission desk on a daily basis, establishing telecommunication with the patients' family to update them on the day's proceedings, addressing concerns of the family within the gamut of optimum management, and providing emotional support to allay their anxiety. Besides, it facilitated in conveying the specific concerns of the family to the treating physician/attending nurse depending on the nature of the concern, and overall coordinating the communication between the treating physicians with the relatives for the very sick patients.

The content of information shared with patients' relatives ranged from current status of the patient, updates on investigations done and procedures being planned, management provided, and any other relevant information. All information was shared by the treating team as shown in - Fig. $\mathbf{1}$.

\section{Results}

The role of the treating physician comprised providing optimal treatment to the COVID-19-positive patients. Further, a documentation and information sharing plan was evolved using online cloud platforms to facilitate an easy exchange of information between rotating treating teams as well as the communication team. The document was updated at least once daily and it summarized the highlights of the day's management. The treating team was also responsible to brief the communication team regarding the pertinent changes in patient's status and management. This was initially done in person and later on evolved to a telephonic one.

Besides, providing medically relevant information to the patients' relatives, other information about the patients were sought after by the relatives. This comprised information regarding food provided, bowel habits, clothes provided, etc. Often these were shared with the relatives who sought these information. The communication team also facilitated the passage of some messages passed on from the relatives to the patients and helped in tracing some missing belongings of the patients. Not only that, the communication team was instrumental in facilitating video calls between the family and the patients. All these helped in addressing the anxiety within the patients' relatives.

The family was on the receiving end of the communication chain. The family members would often ask pertinent questions or express specific concerns regarding the disease and/or the patient or their ongoing treatment. These were skillfully addressed by the communication team, individualizing the response depending upon the capability of understanding amongst the relatives. This resulted in developing a rapport between the team and the family and in thus, gaining trust and allaying the anxiety of the relatives.

The major way of communication happened over phone. Initially, the communication team was provided with one landline through which patients' relatives called and were briefed about the patients' status. Later on, the team was provided with two mobile phones. These mobile phones were used to call all patients admitted in our ICUs and were critically ill. The landline was left exclusively for incoming calls.

The communication team often had to brief the patients' relatives through in-person communication. This was because some patients' relatives did not have phone numbers registered in the database. Thus, they could not be called by the communication team. However, gradually, the face-toface briefings were done away with. This resulted in lessening of exposure for both the relatives of the patient and the doctors in the communication group.

During the process of setting up of the communication process at our tertiary care hospital, several challenges had to be overcome. These are listed in -Table 1.

\section{Discussion}

The preventive strategies for the spread of the novel coronavirus transmission necessitate the need for restricting the interaction of common people with healthcare workers. This

Table 1 Challenges and solutions during the development of the communication program

\begin{tabular}{|l|l|l|}
\hline Challenges & Explanation & Solutions \\
\hline Loss of information & $\begin{array}{l}\text { Information travelled from the physician } \\
\text { to the computer and the communication } \\
\text { team, who gathered information from all } \\
\text { physicians before passing it on to the } \\
\text { relatives. Some information got lost in the } \\
\text { process. }\end{array}$ & $\begin{array}{l}\text { The information was entered in a specific } \\
\text { format and the treating physicians would } \\
\text { do an in-person briefing to the } \\
\text { communication team. }\end{array}$ \\
\hline Limited hours of communication & $\begin{array}{l}\text { The communication was done only after } \\
\text { the clinical rounds by the treating } \\
\text { physician were completed. }\end{array}$ & $\begin{array}{l}\text { Critical information to the relatives was } \\
\text { delivered first hand from the ICUs/ } \\
\text { HDUs/wards at any hour. }\end{array}$ \\
\hline $\begin{array}{l}\text { Disconnect between what is } \\
\text { important to the doctor vs. relatives }\end{array}$ & $\begin{array}{l}\text { Most relatives were interested in the } \\
\text { information other than what the } \\
\text { physicians often concentrated on such as } \\
\text { eating/talking/bowel emptying. }\end{array}$ & $\begin{array}{l}\text { Communication team gathered the } \\
\text { specific information during the in-person } \\
\text { briefing with the treating physicians. }\end{array}$ \\
\hline No real-time updates & $\begin{array}{l}\text { The updates were done once a day. There } \\
\text { was a risk of missing vital information. }\end{array}$ & $\begin{array}{l}\text { Real-time, critical information was given } \\
\text { first hand from the ICUs, HDUs, and wards. }\end{array}$ \\
\hline
\end{tabular}

Abbreviations: HDU, high-dependency unit; ICU, intensive care unit. 
is because the doctors, nurses, and other paramedics are coming in close contact with the patients for the purpose of patient care management. Although they are using protective gears in the form of PPE as appropriate for the risk, still there is a chance that they might be a potentially unidentified source of infection to the community, if they remain asymptomatic. Thus, a face-to-face, two-way communication between the treating physicians and the patients' relatives is also most often avoided. In contrast, infection among healthcare workers leads to a shortage of experienced staff to take care of high patient load due to COVID-19 as well as nonCOVID-19 causes. ${ }^{7}$ This cycle may be ignited at any point of time and at any place in a hospital where practice of social distancing may not be feasible, like in the operation theater or emergency service room, where multiple personnel participate in patient care at a time. Hence, it is prudent that a communication strategy may be devised without additional exposure to our specialist doctors and other healthcare staff. Any lapse in the preventive measures may result in infection spread between patients or their attendants and healthcare workers and among healthcare workers.

This unprecedented condition of lack of interaction with their admitted relatives, as well as the unpredictability of the course of the disease is often a source of great stress and anxiety amongst the near and dear ones of the patient. The concern easily transcends from anxiety to panic. The overall situation sometimes leads to verbal and physical abuses on healthcare workers.

In contrast, the healthcare infrastructure, worldwide, has faced tremendous stress. With insufficient preparation, healthcare providers are facing a high volume of severely ill patients requiring advanced life support in ICUs. Due to lack of adequate numbers of trained manpower, healthcare workers are stressed with long work hours, lack of consensus knowledge, and an inherent fear of getting infected themselves, and further transmitting it to their families. Healthcare workers directly associated with the care of COVID-19 patients must use stringent measures including meticulous use of PPE throughout their stay in the specific treatment rooms/wards and ICUs. The discomfort and physical strain of working with the PPE donned has been widely reported in recent times. The sequence of detailed donning, exhaustive work of managing COVID-19 patients with a shortage of manpower followed by careful and time-consuming process of doffing make the treating physicians emotionally stressed and physically exhausted. Frequent change of front-line healthcare providers every 6 to 8 hours makes it difficult to keep a track of the patients' status for all the staff involved in patient care. This adds as a barrier in effective communication between treating doctors and patients' families.

Under ideal circumstances, the desired and most appropriate person to communicate about a patient's disease, treatment, response to treatment and prognosis, to the patient's family is an experienced member from the treating team, which is generally practiced worldwide., ${ }^{8,9}$ This generates confidence amongst patients' families. However, the applicability of this system for hospitalized COVID-19 patients is associated with the concerns as mentioned above, more so in hospitals with limited resources. Hence, a link between the treating team and the patients' family for communication of patients' disease status and relatives' concerns may be considered as the next best possible scenario.

Due to the unpredictable nature of the disease and its outcome, communication of the risks involved to the patients' families is a must. Risk communication, as defined by the WHO, is "the exchange of real-time information, advice and opinions between experts and people facing threats to their health, economic or social well-being." 10 Two broad risk models are commonly used. The realist approach is seen to be objective and independent of social context. The second is the social constructionist approach, whereby risk is seen to be interrelated with sociocultural context. ${ }^{11}$ It is increasingly recognized that society, communities, and our patients view risk from a social constructionist approach. ${ }^{12}$ Communication stands on three important pillars-the source, the message, and the receiver. In the current context, the source of the communication is the treating physician, message is the content of the conversation, and the receiver is the family. It is not surprising that the quality of the conversation between the treating physician and the family varies due to several factors as mentioned above. To combat these inefficiencies, a novel system was designed in our tertiary care hospital. Our novel system comprised another layer: an interface between the treating physician and the family-“a communication team."

\section{Conclusion}

The effectiveness of the communication team and the novel communication process has manifold advantages. Foremost amongst these is the addressal of anxiety of the patients' relatives. The relatives were reassured on a daily basis, through the communication team about the progress of the patient. The communication team here consisted of senior doctors coming from diverse specialty backgrounds. This was quite reassuring for patients' relatives. Besides, it helped in appropriate utilization of doctors from specialties not directly dealing with patients. This, in turn, provided relief to doctors who were directly involved in patient care. The treating doctors were thoroughly exhausted post-doffing after taking clinical rounds. The communication team helped them relieve from their duties earlier, thus helping in preventing over-exhaustion and breakdown. However, the novel system sometimes generated some gaps in communication. Because the information passed on was not in realtime, this sometimes led to confusion. The clinical updates were received from all wards and ICUs at a specific time of the day, after which the family was informed. Any amendments made in the plan of management were reflected on the next day, putting the family at risk of receiving misinformation regarding shift of patients from ICU to ward or vice versa.

Despite facilitating telecommunication through this novel method, some extremely apprehensive attendants invariably desired to see/talk to their patients. Hence, setting up of a 
video-calling facility for patients was suggested by the communication team to the administration. Besides, to facilitate the communication team it was advised that the patient database could be crafted to enable a calling link for direct calling instead of dialing the numbers. This would greatly cut down on the time spent on procuring telephone numbers and calling from separate phones.

In conclusion, an intermediate team can be set up in each COVID-19 treating hospital facility to facilitate communication between the treating physician and the patient's family. This little thought may work a long way in obviating unnecessary panic in the minds of the family of the indoor COVID-19 positive patients.

\section{Conflict of Interest}

None declared.

\section{References}

1 Zhu N, Zhang D, Wang W, et al; China Novel Coronavirus Investigating and Research Team. A novel coronavirus from patients with pneumonia in China, 2019. N Engl J Med 2020;382(08):727-733

$2 \mathrm{Lu} \mathrm{H}$, Stratton CW, Tang YW. Outbreak of pneumonia of unknown etiology in Wuhan, China: the mystery and the miracle. J Med Virol 2020;92(04):401-402

3 Situation WHO. Report-198 [Internet]. Accessed August 6, 2020 from: https://www.who.int/docs/default-source/coronaviruse/ situation-reports/20200805-COVID-19-sitrep-198.pdf? sfvrsn=f99d1754_2

4 Transmission of SARS-CoV-2: implications for infection prevention precautions [Internet]. Accessed August 25, 2020 from: https://www.who.int/news-room/commentaries/detail/trans- mission-of-sars-cov-2-implications-for-infection-preventionprecautions

5 Li YH, Fan YZ, Jiang L, Wang HB. Aerosol and environmental surface monitoring for SARS-CoV-2 RNA in a designated hospital for severe COVID-19 patients. Epidemiol Infect [Internet]. 2020 ed;148. Accessed August 25, 2020 from: https://www.cambridge. org/core/journals/epidemiology-and-infection/article/aerosoland-environmental-surface-monitoring-for-sarscov2-rna-in-adesignated-hospital-for-severe-COVID-1919-patients/65E19D9 F230995CD82102C200EC790DD

6 Nguyen LH, Drew DA, Graham MS, et al; COronavirus Pandemic Epidemiology Consortium. Risk of COVID-19 among front-line health-care workers and the general community: a prospective cohort study. Lancet Public Health 2020;5(09):e475-e483

7 Amid govt efforts to increase COVID-19 bed numbers, hospitals face shortage of health workers [Internet]. 2020. Accessed August 25, 2020 from: https://www.outlookindia.com/newsscroll/ amid-govt-efforts-to-increase-COVID-19-bed-numbers-hospitalsface-shortage-of-health-workers/1877020

8 Hickey M. What are the needs of families of critically ill patients? A review of the literature since 1976. Heart Lung 1990;19(04): 401-415

9 Heyland DK, Rocker GM, Dodek PM, et al. Family satisfaction with care in the intensive care unit: results of a multiple center study. Crit Care Med 2002;30(07):1413-1418

10 World Health OrganizationGeneral information on risk communication [Internet]. WHO. World Health Organization;]. Accessed August 11, 2020 from: https://reliefweb.int/report/world/ communicating-risk-public-health-emergencies-who-guidelineemergency-risk-communication

11 Responding to global infectious disease outbreaks: lessons from SARS on the role of risk perception, communication and management. Social Science \& Medicine 2006;63(12):3113-3123

12 Abrams EM, Greenhawt M. Risk Communication During COVID-19. J Allergy Clin Immunol Pract 2020;8(06):1791-1794 